\title{
PI Fuzzy Controller of Synchronous Boost Converter for Drug Storage Thermoelectric Cooler
}

\author{
Alvin Noer Ramadhan \\ Department of Electrical Engineering \\ Politeknik Elektronika Negeri Surabaya \\ Surabaya, Indonesia \\ alvinnr9@gmail.com
}

\author{
Novie Ayub Windarko \\ Department of Electrical Engineering \\ Politeknik Elektronika Negeri Surabaya \\ Surabaya, Indonesia \\ ayub@pens.ac.id
}

\author{
Irianto \\ Department of Electrical Engineering \\ Politeknik Elektronika Negeri Surabaya \\ Surabaya, Indonesia \\ irianto@pens.ac.id
}

\begin{abstract}
Medicines should be stored in a room at a suitable temperature because the condition of temperature affects the quality of the drug. Improper storage procedures may result in the drug being unable to cure effectively and cause drug damage which results in losses for pharmaceutical industry companies and patients. Therefore a controller for temperature is needed in the room so that it is constantly under the rules of room temperature for drug storage, which is 25 degrees Celsius. The following paperwork presents a simulation controller between PI controller and PI-Fuzzy logic controller in adjusting the voltage to match the set of points. The fuzzy logic controller automatically searches $\mathrm{Kp}$ value so the voltage output of the converter matches the desired set of points. The converter used is a synchronous boost converter as a voltage regulator and Peltier as a DC load which functions as a cooler. In this research, the system using PI controller was able to adjust the voltage to match the set point $60 \mathrm{~V}$ with $K_{P}$ is 0.14089 , $K i$ is 125.6738 , and the settling time is 0.016 s. While the system using PI-Fuzzy logic controller, it was able to adjust the voltage to match the set point $60 \mathrm{~V}$ with $\mathrm{Kp}$ is $0.08112, K_{\mathrm{i}}$ is 125.6738, and settling time is $0.014 \mathrm{~s}$. It can be concluded that the PI Fuzzy controller can find the $K_{P}$ value automatically and reach the desired set point.
\end{abstract}

Keywords—peltier, PI cotroller, PI-fuuzzy logic controller, synchronous boost converter

\section{INTRODUCTION}

The storage of pharmaceutical products is one of the necessary steps in maintaining the quality of medicines. One of the factors that influence storage conditions is temperature. Drugs must be stored at a suitable temperature to prevent deterioration of the quality of the drug. The required temperature for the room itself is 25 degrees Celsius. But in fact, many medicines are stored above 30 degrees Celsius[1].

Based on the problems that occur, this paper presents the PI-fuzzy logic control in which the control does not require complex mathematical modeling and it is very suitable in settings such as temperature. The cold temperature coming out of the peltier will be regulated by the PI-fuzzy logic controller to comply with the drug storage temperature rules, which is 25-degree Celsius [2]. The advantage of using Peltier is its ability to cool below ambient and its environmental friendliness. Different from conventional refrigeration systems that cannot be fabricated without chlorofluorocarbons or other chemicals that may be harmful to the environment, thermoelectric devices do not use or generate gases of any kind.
The reference in regulating temperature according to [3] is using PID Controller. This paper describes the comparison of the temperature response using and not using a PID controller. From the results acquired when using the PID controller, the temperature response reaches the set point faster than without control. Furthermore, the effectual dissipation of the hot side also affects the cold side of the Peltier. The reference in regulating temperature according to [4] describes the function of the artificial neural network as a cold temperature regulation produced by Peltier. Where this control is compared with regulatting peltier cold temperature which performance is under the influence of convective airflow at different power input levels. And the results show that the performance of the thermoelectric cooler is greatly influenced by frequency waves at different values of power input. and comparing with ANN the result is a good match.

The novelty of this research is using the PI-Fuzzy controller to change complex mathematical modeling into basic mathematical modeling by applying the fuzzy logic tools and the output of the PI-Fuzzy logic controller that is capable of automatically finding the value of $K_{P}$. The cooling method of drugs uses peltier and the main purpose of using Peltier is to reduce the use of freon which is often used by pharmacies to store drugs which it has a very bad impact on the environment. Then the cold temperature produced by the peltier will be regulated by the PI-Fuzzy logic controller [5].

The way fuzzy logic works broadly consists of inputs, processes, and outputs. Fuzzy logic is a set of logic theories developed to overcome the concept of value between truth (truth) and error (false). By using fuzzy logic produced not only yes (1) or no (0) but all possibilities between 0 and 1 so that there is no significant change found in the fuzzy control logic system that works between 0 and 1 [6].

\section{Research Methodology}

\section{A. Synchronous Boost Converter}

The synchronous boost converter is a DC-DC converter where the output voltage is greater than the input voltage. This converter uses two MOSFETs where the two MOSFETs in a synchronous converter must have the same frequency and do not work simultaneously. Changing the diode to a MOSFET is expected to reduce power loss in the DC to DC converter because the Mosfet has a low internal resistance (active Rds) during conduction mode [7]. The following Figure 1 synchronous boost converter circuit. 


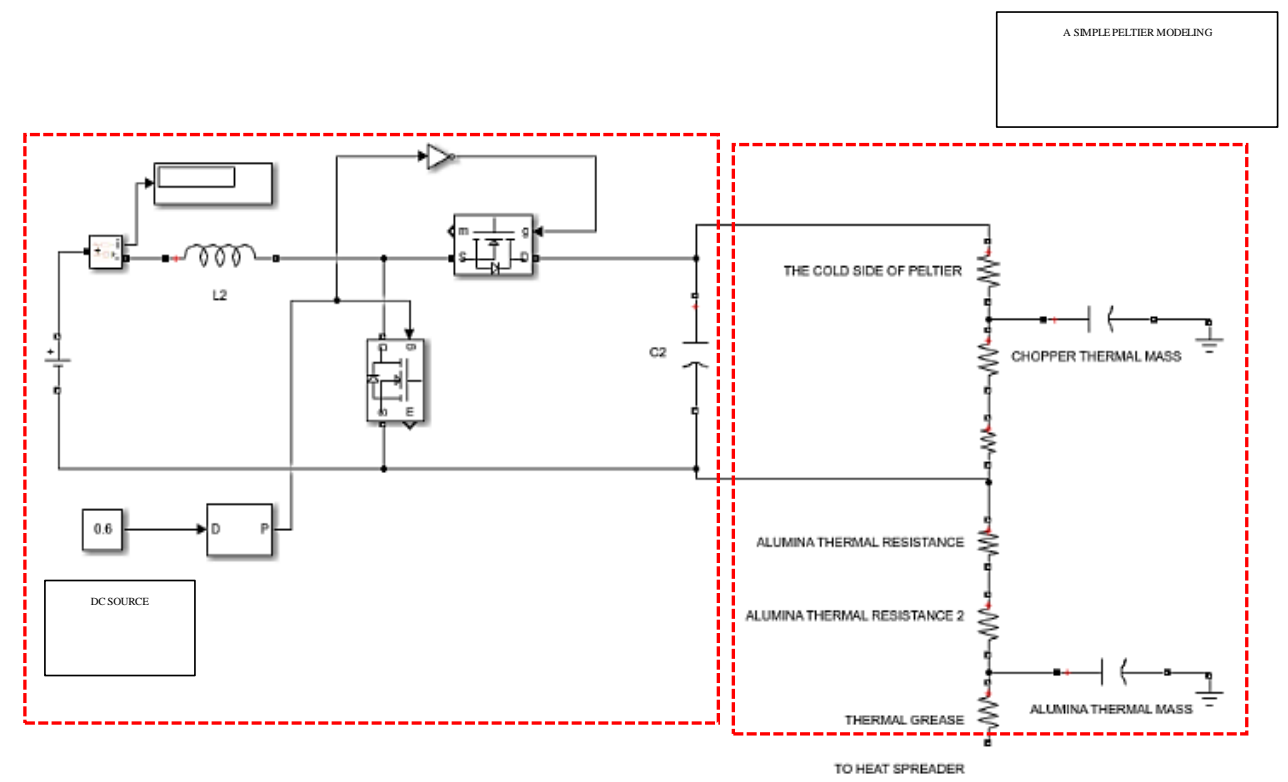

Fig. 1. Synchronous boost converter circuit with peltier load

$$
\begin{aligned}
& \mathrm{V}_{\mathrm{o}}=\frac{\mathrm{V}_{\mathrm{o}}-\mathrm{V}_{\text {in }}}{\mathrm{D}} \\
& \mathrm{L}=\frac{1}{\mathrm{~F}} \times\left(\mathrm{V}_{\mathrm{o}}+\mathrm{V}_{\mathrm{f}}\right) \times\left(\frac{\mathrm{V}_{\text {in }}}{\left(\mathrm{V}_{\mathrm{o}}+\mathrm{V}_{\mathrm{f}}\right)}\right) \times\left(\frac{1}{\Delta \mathrm{I}_{\mathrm{L}}}\right) \\
& \mathrm{C}=\frac{\mathrm{I}_{\mathrm{crms}} \times \mathrm{D} \times \mathrm{T}}{\Delta \mathrm{V}_{\mathrm{o}}}
\end{aligned}
$$

The meaning of the symbol above is as follows:

$\mathrm{V}_{\mathrm{o}} \quad$ : Output voltage $(\mathrm{V})$

$\mathrm{V}_{\text {in }}$ : Input voltage $(\mathrm{V})$

D : Duty cycle $(\%)$

L : Inductor $(\mathrm{H})$

$\mathrm{V}_{\mathrm{f}} \quad$ : Forward voltage $(\mathrm{V})$

C : Capacitor $(\mathrm{F})$

$\Delta \mathrm{I}_{\mathrm{L}} \quad$ : Inductor current ripple

$\mathrm{F} \quad$ : Frequency $(\mathrm{Hz})$

Details of Synchronous Boost Converter specification on the system that is proposed to serve in Table 1.

TABLE I. SPESIFICATION DATA OF SYNCHRONOUS BOOST

\begin{tabular}{|l|l|}
\hline \multicolumn{1}{|c|}{ Parameter } & \multicolumn{1}{c|}{ Value } \\
\hline Switching Frequency (f) & $20 \mathrm{KHz}$ \\
\hline Input Voltage (Vs) & $24 \mathrm{~V}$ \\
\hline Output Voltage (Vo) & $60 \mathrm{~V}$ \\
\hline Inductor (L) & $393.495 \mu \mathrm{H}$ \\
\hline Capacitor (C) & $2957.4 \mu \mathrm{F}$ \\
\hline
\end{tabular}

\section{B. Control PI-Fuzzy Logic Controller}

There are several steps at the fuzzy controller planning stage: determining the membership function, the form of the membership function, and the output membership function. The fuzzy controller in the system acts as a regulator of the $\mathrm{K}_{\mathrm{p}}$ value on the PI controller. When the fuzzy logic controller can tune the value of $K_{p}$, it can speed up the response to the set points [5]. Thus, in this system, the value of $\mathrm{K}_{\mathrm{p}}$ will be a fuzzy output membership function.

The advantage of the fuzzy logic controller in tuning the value of $K_{p}$ is its capability to speed up the settling time response because it requires a long time for the temperature to reach the set points. So it is expected that the value of $\mathrm{K}_{\mathrm{p}}$ is tuned by the fuzzy logic controller in order to speed up the response. Then, the PI-Fuzzy controller can reduce overshoot and become more stable. The following Figure 2 diagram block PI-Fuzzy controller.

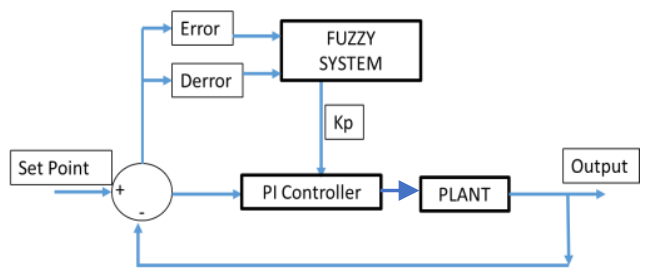

Fig. 2. Fuzzy logic controller structure

Fuzzy design which consists of a fuzzy interface system design process includes: a) design input membership function, b) design output membership function, c) design rule base.

It can be seen in Figure 2 that the output of fuzzy will produce 1 output, in which the output of fuzzy is the value of $K_{p}$. There are 2 input variables in fuzzy: error and delta error. The error is the difference between the set point voltage and the measured voltage. Then the delta error is the difference between the current error and the previous error [5].

To determine the membership function of fuzzy input in this system, fuzzy control changes the value of the gained $K_{p}$. When the set point changes, the input membership function must represent the value of error and delta error. The membership function of error and delta error is shown in Figure 3 and Figure 4. 


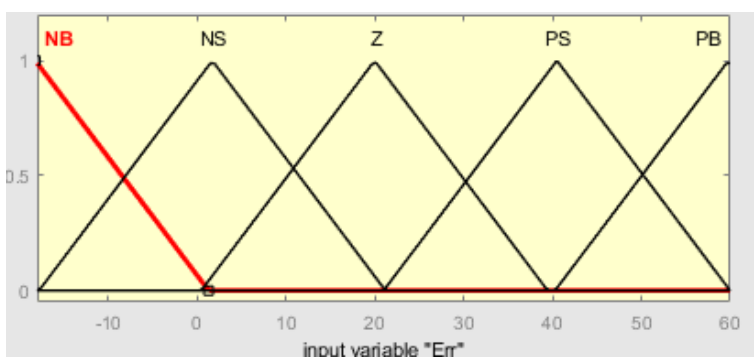

Fig. 3. Design membership function input (error)

The input membership function in this system uses a full symmetric triangular representation. In order to obtain linear up and down linear transfer characteristics, 3 linguistics are used. Upward linear representation is the increase of the set starting from the value of domain which has a membership value of zero moves to the right to the value of domain that has a higher degree of membership. A downward linear representation is a straight line that starts from the value of the domain with the highest degree of membership on the left, then moves down to the value of the domain with a lower degree of membership.

For the singleton output fuzzy, the value is determined from the $K_{P}$ value using the second order calculation PI control which is used as a reference of the minimum value and maximum value of the fuzzy output. The use of singleton fuzzy output is easy to apply in a microcontroller and has a simple defuzzyfication algorithm. In defuzzyfication, all significant fuzzy outputs will be combined into variables. One of the defuzzyfication techniques used in this system is Weight Average. In this method, the value of each output membership function indicated by each fuzzy output is truncated. Using the weight average fuzzyfication method, the output singleton values are combined using average weights $[5,6]$. The weight average formula for calculation is:

$$
\mathrm{X}^{*}=\frac{\sum \mu(X) \times X}{\sum \mu(X)}
$$

Where $\sum \mu(X)$ is the membership function and $X$ is the degree of membership. The following Figure 5 is the design membership function output variables.

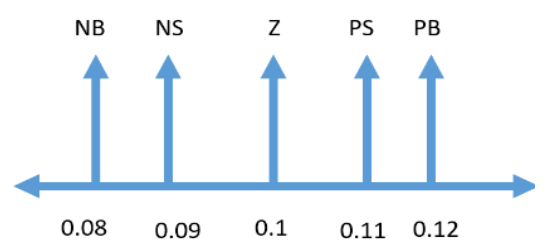

Fig. 5. Design membership function output variables

In Figure 5 for the crisp value, it can be seen that the range is made between 0.08 and 0.12 so that the defuzzification process results in one output value.

Since the output from the fuzzy controller is $\mathrm{K}_{\mathrm{p}}$ value that corresponds to the change in the set point, the rule base can be determined by looking at the error and delta error values used as fuzzy input variables. The rule base is used to determine the desired control according to the plant planned by the operator. To determine the rules, we may use relative calculations or the "truth value" of each rule.

For the decision-making method used in fuzzy, that is the Takagi Sugeno Kang (TSK) method or the Sugeno

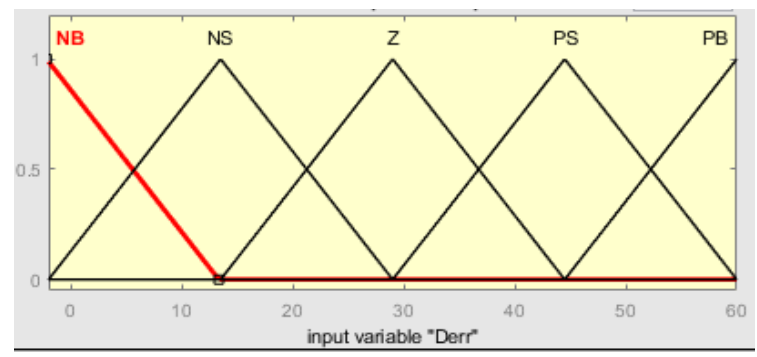

Fig. 4. Design membership function input (delta error)

Method, the rules are represented in the form of IF-THEN and the output or consequences of the system are not in the form of fuzzy sets, but in the form of constants or linear equations [8].

The reason for using the rule base 25 is because it has a better response than the open loop response. Output voltage response without using control has a very large ripple. However, when using a fuzzy controller with a rule base of 25 rules, the resulting ripple voltage can be minimized. The more rule base is used, the response of fuzzy output is better. The Rule base is shown in table 2 .

TABLE II. RULE BASE

\begin{tabular}{|c|c|c|c|c|c|}
\hline E/ $\Delta \mathrm{E}$ & NB & NS & $\mathbf{Z}$ & PS & PB \\
\hline NB & NB & NB & PS & PS & PS \\
\hline NS & NB & NS & PS & PS & PS \\
\hline $\mathbf{Z}$ & NS & NS & Z & PS & PS \\
\hline PS & NS & NS & NS & PS & PB \\
\hline PB & NS & NS & NS & PB & PB \\
\hline
\end{tabular}

\section{PI Controller}

This system concentrates on setting the output voltage on a synchronous boost converter in which the output voltage is constant. With this condition, the controller used is a PI controller so that the output voltage from the converter is constant. To be able to know the values of $K_{p}$ and $\mathrm{K}_{\mathrm{i}}$, the output voltage response of the converter must be shown at first. Figure 6 shows the result of the converter's response so that the parameter value of the PI control can be determined using the second order formula $[9,10]$.

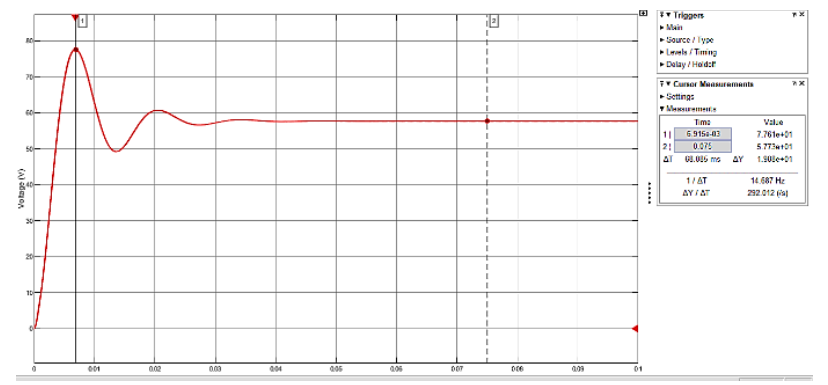

Fig. 6. Curve output voltage synchronous boost converter

TABLE III. PARAMETERS TO FIND THE VALUE $\mathrm{K}_{\mathrm{P}}$ AND $\mathrm{K}_{\mathrm{I}}$

\begin{tabular}{|c|c|}
\hline Steady state value & $58.01 \mathrm{~V}$ \\
\hline Setting point & $60 \mathrm{~V}$ \\
\hline Peak Time $\left(\mathrm{T}_{\mathrm{p}}\right)$ & $0.01 \mathrm{~s}$ \\
\hline Settling time $\left(\mathrm{T}_{\mathrm{s}}\right)$ & $0.061 \mathrm{~s}$ \\
\hline
\end{tabular}

Based on table 3, to determine the value of $\mathrm{Kp}$ and $\mathrm{Ki}$, we can use the second order analytical formula as follows[11]: 


$$
\begin{aligned}
& \mathrm{T}_{\mathrm{p}}=\frac{\pi}{\omega_{\mathrm{d}}} \\
& \mathrm{T}_{\mathrm{s}}=\mathrm{A} \times \tau \\
& \tau=\frac{1}{\alpha} \\
& \alpha=\xi \times \omega_{\mathrm{n}} \\
& \omega_{\mathrm{d}}=\omega_{\mathrm{n}} \times \sqrt{1-\xi^{2}} \\
& \mathrm{~K}_{\mathrm{p}}=\frac{\tau_{1}}{\tau^{*} \times \mathrm{K}} \\
& \mathrm{K}_{\mathrm{i}}=\frac{\mathrm{K}_{\mathrm{p}}}{\tau_{1}}
\end{aligned}
$$

Where :

$\mathrm{T}_{\mathrm{P}}=$ Time Peak

$\mathrm{T}_{\mathrm{s}}=$ Time settling

$\xi=$ damping ratio

$\omega_{\mathrm{n}}=$ Undamped Natural Frequency

$\alpha=$ Damped Coefficient

$\mathrm{K}=$ Gain over all

From the formula above, the PI control block function is created in Matlab and the results are as shown in figure 7.
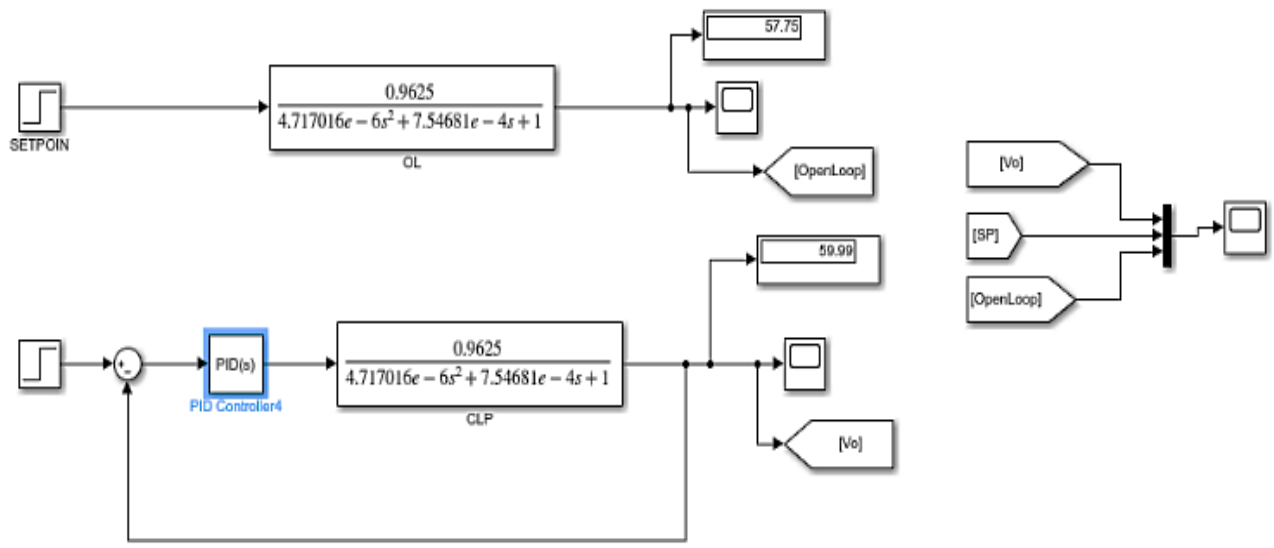

Fig. 7. Function block PI controller

From figure 7 is the function block of the Matlab application producing the response curve results in figure 8 .

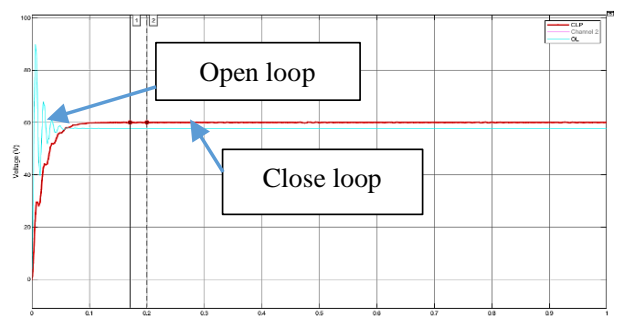

Fig. 8. Response curve PI controller

In figure 8 it can be seen that the blue curve shows an open loop system that has not reached the target of set point, which is $60 \mathrm{~V}$. While the red curve shows a close loop system (PI controller) where there is no overshoot on the curve like the open loop curve, and it has reached the set point which is $60 \mathrm{~V}$.

\section{Thermoelectric (Peltier)}

A thermoelectric cooler is a cooling device that uses the peltier element in the system as a heat pump. The peltier effect occurs when two different metals are connected and the two ends of the metals are maintained at different temperatures. Besides, there will be other phenomena that occur in two metals: the Joule effect, the Fourier effect, the Peltier effect and the Thomson effect.

The principle of the thermoelectric cooler is based on the peltier effect. When DC is applied to a peltier element consisting of several pairs of semiconductor cells of type $\mathrm{P}$ (semiconductor having lower energy level) and type $n$ (semiconductor with higher energy level), one side of the Peltier element will cool (heat is absorbed) and the other side will be hot (heat is released). The side of the peltier element which becomes the hot or cold side depends on the direction of the following electric current in figure 9.

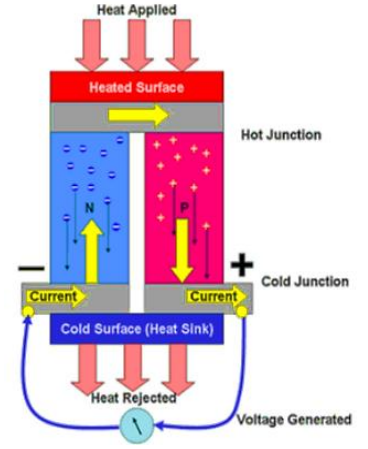

(a)

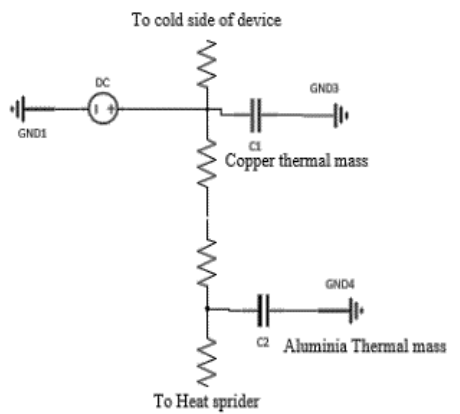

(b)
Fig. 9. (a) The hot and cold sides of peltier (b) A simple peltier modeling

One side of the peltier becomes cool because it flows electrons from a lower energy level in p-type semiconductors, to a higher energy level, namely n-type semiconductors [12]. In order that the p-type electrons which have a lower energy level to flow, the electrons absorb heat which causes the side to become cool. Figure 9 (b) is simple modeling of the Peltier wherein there is an internal resistance in the Peltier that when injected with a DC source, it will produce a hot side and a cold side [13]. If we want to produce a cool temperature, we need to regulate the heat dissipation temperature. The more effective the heat dissipation is, the maximized the cold temperature will be. 


\section{RESULTS AND DisCUSSION}

\section{A. Simulation System}

In this research, the system is simulated using Matlab software. The converter input source uses a DC source where the value of the input is $24 \mathrm{~V}$ and then increased to $60 \mathrm{~V}$. The simulation of a synchronous boost converter using the PI-Fuzzy Logic controller is shown in figure 11.

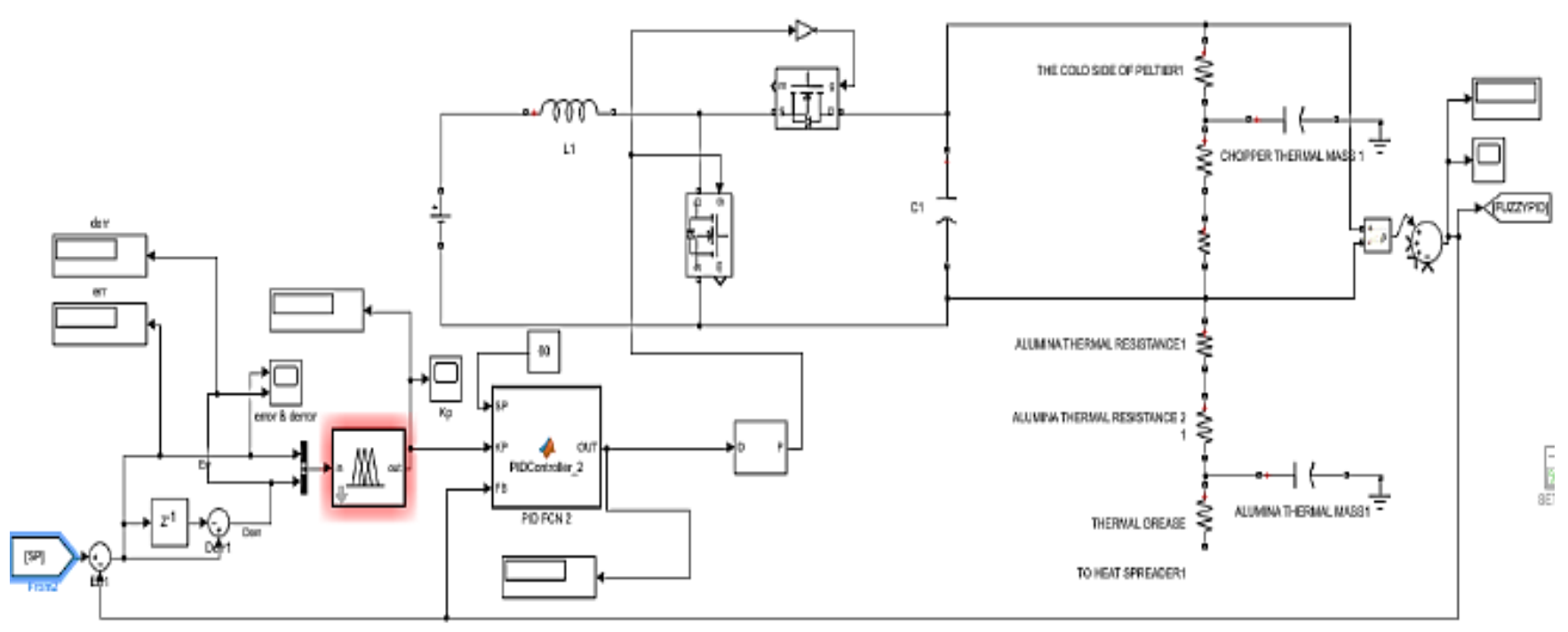

Fig. 10. Synchronous boost converter with PI-fuzzy logic controller

It can be seen from Figure 9 that the output of the fuzzy logic controller is the value of $K_{p}$, and the value of $K_{i}$ is fixed. Thus, the fuzzy logic controller can determine the value of $K_{p}$ itself and the purpose of tuning the value of $K_{P}$ with fuzzy is to speed up the response to reach the setting points. The following is the comparison of the curve between PI and PI-fuzzy logic controller with the set point of voltage is $60 \mathrm{~V}$ in Figure 12.

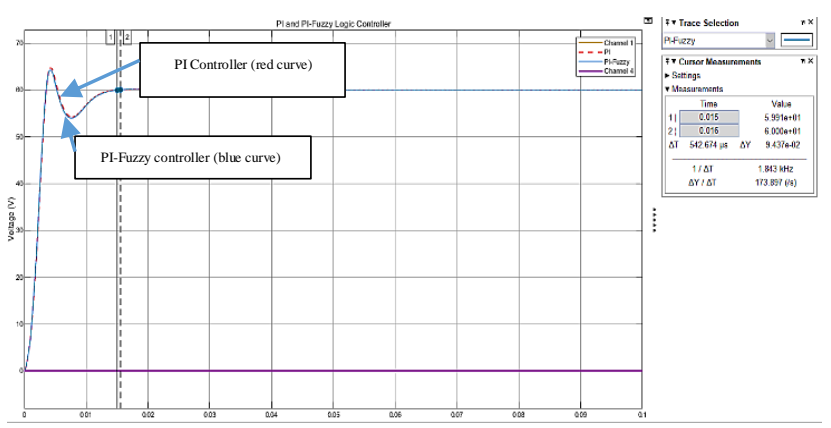

Fig. 11. The comparison of the curve between PI and PI-fuzzy logic controller with set point is $60 \mathrm{~V}$

As shown in Figure 12, the PI-fuzzy logic controller is capable of automatically tunning the value of $K_{P}$. The result is 0.8112 , and the value of $\mathrm{K}_{\mathrm{i}}$ is fixed. The settling time only takes 0.014 seconds. Meanwhile, it takes 0.016 seconds using the PI controller.

Afterward, we change the set point of voltage into $55 \mathrm{~V}$. In figure 13 below is the comparison of the PI and PI-fuzzy logic controller with the set point of voltage is $55 \mathrm{~V}$.

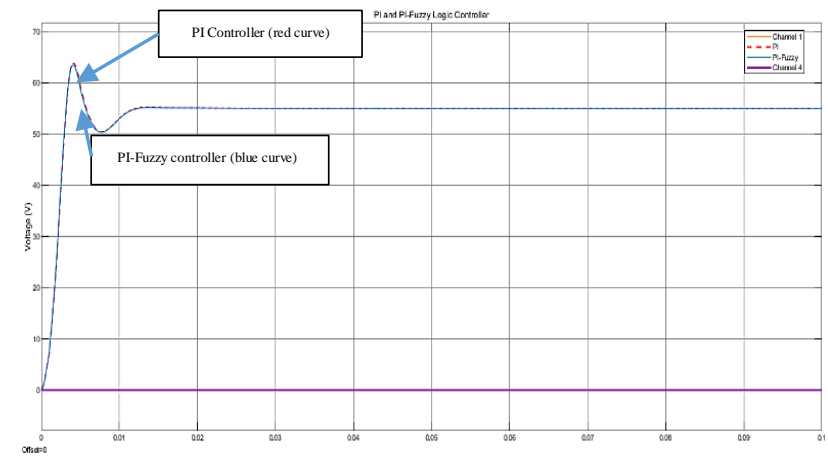

Fig. 12. The comparison of the curve between PI and PI-fuzzy logic controller with set is 55

Figure 13 shows that the PI-fuzzy logic controller is capable of automatically tunning the value of $\mathrm{K}_{\mathrm{P}}$. The result is 0.9182 , and the value of $\mathrm{K}_{\mathrm{i}}$ is fixed. The settling time only takes 0.016 seconds, and it only takes 0.017 seconds using the PI controller. From the simulations that have been carried out, the simulations results of the PI and PI-Fuzzy logic controller are shown in Table 4 and Table 5.

\begin{tabular}{|c|c|c|c|}
\multicolumn{1}{c|}{ TABLE IV. } & \multicolumn{3}{c|}{ SIMULATION RESULTS USING PI CONTROLLER } \\
\hline Set Point & $\begin{array}{c}\text { Rise Time } \\
\text { (Second) }\end{array}$ & $\begin{array}{c}\text { Settling Time } \\
\text { (Second) }\end{array}$ & $\begin{array}{c}\text { Maximum } \\
\text { Overshoot }\end{array}$ \\
\hline $60 \mathrm{~V}$ & 0.003547 & 0.016 & $64.69 \mathrm{~V}$ \\
\hline $55 \mathrm{~V}$ & 0.003198 & 0.017 & $63.79 \mathrm{~V}$ \\
\hline
\end{tabular}

TABLE V. SIMULATION RESULTS USING PI-FUZZY LOGIC

\begin{tabular}{|c|c|c|c|}
\hline \multicolumn{5}{|c}{ CONTROLLER } \\
\hline Set Point & $\begin{array}{c}\text { Rise Time } \\
\text { (Second) }\end{array}$ & $\begin{array}{c}\text { Settling Time } \\
\text { (Second) }\end{array}$ & $\begin{array}{c}\text { Maximum } \\
\text { Overshoot }\end{array}$ \\
\hline $60 \mathrm{~V}$ & 0.003226 & 0.014 & $64.21 \mathrm{~V}$ \\
\hline $55 \mathrm{~V}$ & 0.003197 & 0.016 & $63.42 \mathrm{~V}$ \\
\hline
\end{tabular}

Table 4 and Table 5 show a comparison of the responses between PI and PI-Fuzzy logic controller. As indicated in the table, when the set point is $60 \mathrm{~V}$ with PI control, the required rise time is 0.003547 seconds. The rise time is 
defined as the time required for a response increases from $10 \%$ to $90 \%$ of the set point. Furthermore, when using the PI-Fuzzy logic controller, the rise time obtained is 0.003226 seconds. Also, the PI-fuzzy logic controller has a better maximum overshoot than the PI controller.

What is meant by maximum overshoot is the difference between the maximum values achieved by the response to the set point. When the set point is $55 \mathrm{~V}$ with PI control, the required rise time is 0.003198 seconds. Then, when using the PI-Fuzzy logic controller, the rise time obtained is 0.003197 seconds. To find out whether the fuzzy logic controller design is appropriate, this paper shows an example of a simple calculation as follows:

If the crisp value received by the error is 25 and the crisp value received by the delta error is 35 , it can be calculated using the triangle membership formula in Figure 14.

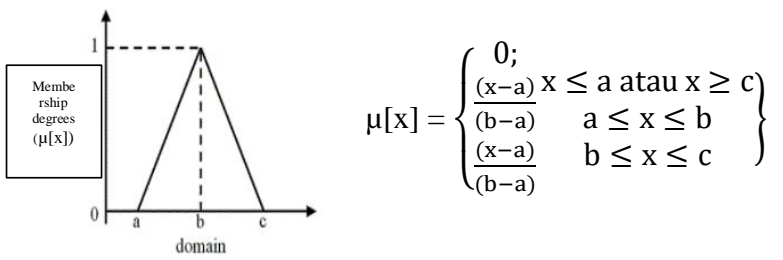

Fig. 13. Triangle membership function formula

Then for the error is 25 in the eZ and ePS functions, see Figure 15.

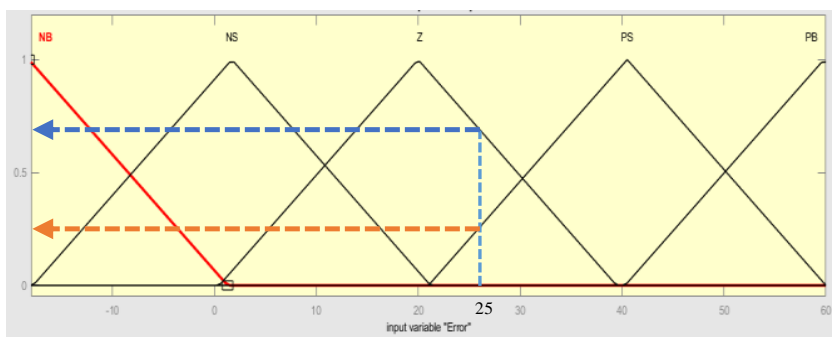

Fig. 14. The error is 25 in eZ and ePS function

Error (eZ):

$\mu_{\mathrm{e}}(25)=\frac{\mathrm{c}-\mathrm{x}}{\mathrm{c}-\mathrm{b}}=\frac{39.45-25}{39.45-19.98}=0.742$

Error (ePS):

$\mu_{\mathrm{e}}(25)=\frac{\mathrm{x}-\mathrm{a}}{\mathrm{b}-\mathrm{a}}==\frac{25-21}{40.5-21}=0.205$

Then for the delta error is 35 in the $\mathrm{dZ}$ and dPS functions, see Figure 16.

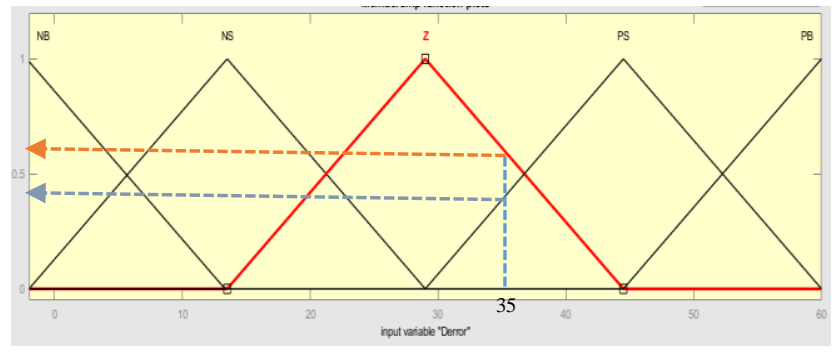

Fig. 15. The error is $35 \mathrm{in} \mathrm{dZ}$ and dPS function

Delta error $(\mathrm{dZ})$ :

$\mu_{\mathrm{e}}(35)=\frac{c-x}{c-b}=\frac{44.5-35}{44.5-29}=0.612$
Delta error (dPS):

$\mu_{\mathrm{e}}(35)=\frac{\mathrm{x}-\mathrm{a}}{\mathrm{b}-\mathrm{a}}==\frac{35-29}{44.5-29}=0.387$

So the fuzzyfication process results,

Error $\quad=\mathrm{Z}(0.742)$ dan $\operatorname{PS}(0.205)$

Delta Error $=\mathrm{dZ}(0.612)$ dan $\operatorname{dPS}(0.387)$

From the four fuzzy input data above, two rules with "min inference" can be applied to the fuzzy logic rule base control.

$$
\begin{aligned}
\mu_{\mathrm{R}}(13) & =\mathrm{e} Z \cap \mathrm{dZ}=\mu_{\mathrm{e}}(25) \cap \mu_{\mathrm{e}}(35) \\
& =0.742 \cap 0.612=0.612 \\
\mu_{\mathrm{R}}(14) & =\mathrm{eZ} \cap \mathrm{dPS}=\mu_{\mathrm{e}}(25) \cap \mu_{\mathrm{e}}(35) \\
& =0.742 \cap 0.387=0.387 \\
\mu_{\mathrm{R}}(18) & =\mathrm{ePS} \cap \mathrm{dZ}=\mu_{\mathrm{e}}(25) \cap \mu_{\mathrm{e}}(35) \\
& =0.205 \cap 0.612=0.205 \\
\mu_{\mathrm{R}}(19) & =\mathrm{ePS} \cap \mathrm{dPS}=\mu_{\mathrm{e}}(25) \cap \mu_{\mathrm{e}}(35) \\
& =0.205 \cap 0.387=0.205
\end{aligned}
$$

The defuzzification process uses the weight average method in which the method takes the average value by using a weighting in the form of membership degrees. So that $\mathrm{X}^{*}$ can be calculated using (4) below:

$$
\begin{aligned}
& X^{*}=\frac{(\mu 13 \times \mathrm{oZ})+(\mu 14 \times \mathrm{oPS})+(\mu 18 \times \mathrm{oNS})+(\mu 19 \times \mathrm{oPS})}{\mu 13+\mu 14+\mu 18+\mu 19} \\
& X^{*}=\frac{(0.612 \times 0.1)+(0.387 \times 0.11)+(0.205 \times 0.09)+(0.205 \times 0.11)}{0.612+0.387+0.205+0.205} \\
& X^{*}=0.103
\end{aligned}
$$

Then the output crisp value is 0.103 , with the input crisp error 25 and delta error 35. so that to make sure the calculation is correct, it can be compared with the simulation results, as in Figure 17.

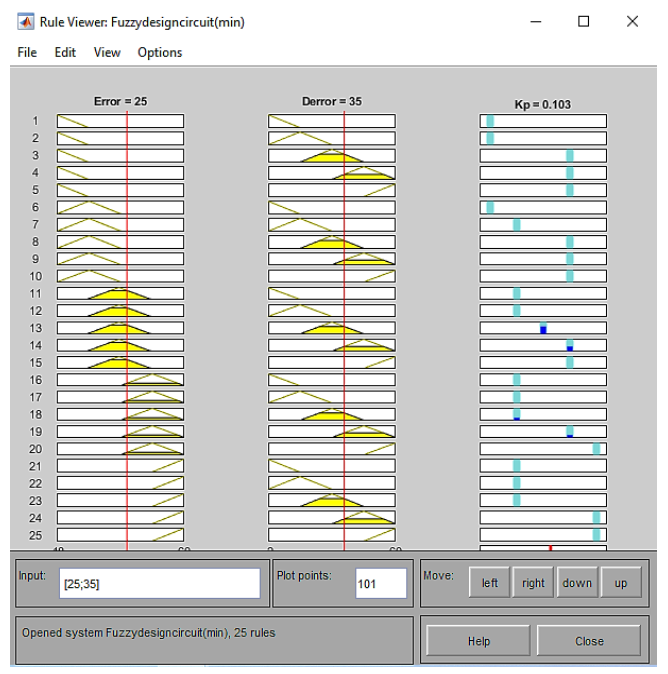

Fig. 16. Rule viewer

Then, to test whether the controller is capable to return to the set point, interference is given with three conditions: the conditions when the voltage is more than the set point, the conditions when the voltage is less than the set point, and the conditions when the voltage rises and falls. 
The following Figure 18 indicates that the PI-Fuzzy controller wave when the voltage is more than the set points. Then, in Figure 19, the PI-Fuzzy controller wave when the voltage is less than the set points. In Figure 20, the output wave from the PI-Fuzzy controller when it is given an up and down voltage disturbance.

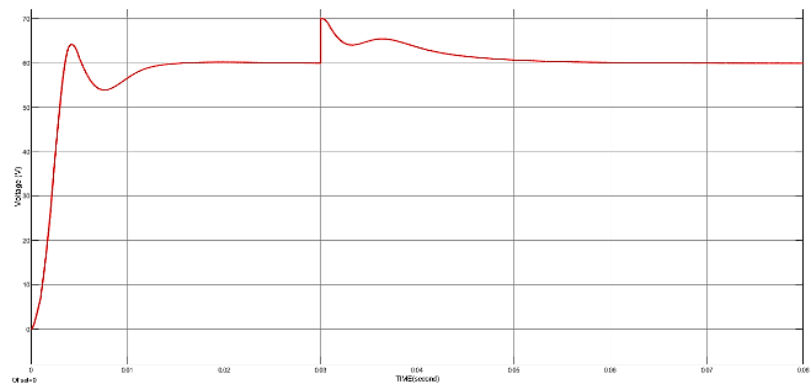

Fig. 17. PI-fuzzy controller wave when the voltage is more than the set points

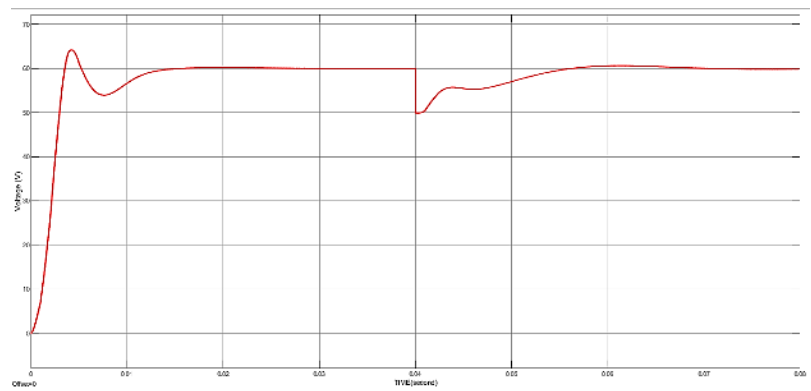

Fig. 18. PI-fuzzy controller wave when the voltage is less than the set points

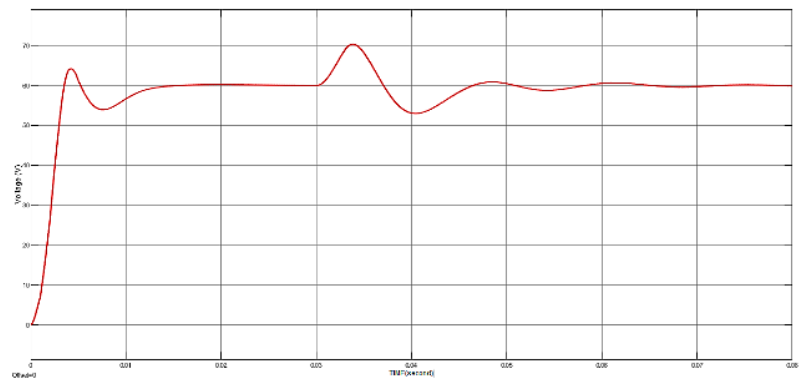

Fig. 19. The output wave from the PI-fuzzy controller when given an up and down voltage disturbance

From the conditions of three disturbances above, it can be seen that the PI-Fuzzy control can return according to the set point, namely 60 volts. It has shown the ability of the PI-Fuzzy control to be able to automatically change the $\mathrm{Kp}$ value according to the design that has been made.

\section{CONCLUSION}

From the simulation resulting in a comparison between PI and PI-fuzzy logic controller on a synchronous boost converter using Matlab, it can be concluded that:

1. The simulation of synchronous boost converter with PI control has been able to reach the set point of $60 \mathrm{~V}$ where the $\mathrm{Kp}$ value is 0.14089 and the $\mathrm{Ki}$ value is 125.6738 .

2. In the PI-Fuzzy logic controller simulation, the output of the fuzzy controller is the value of $K_{P}$, wherein the fuzzy controller is able to automatically change the value of $K_{P}$. The result value from the fuzzy output is 0.08112 .

3. In the PI-Fuzzy logic controller simulation, if there is a disturbance on the output converter when the voltage is more than the set point, the PI-Fuzzy control is able to return to the original set point. If the voltage is less than the set point, the PI-Fuzzy control is able to return to the original set point.

\section{REFERENCES}

[1] M.Ponni, and Dr.R.Baskar, "A Study on Indoor Temperature and Comfort Temperature, "International Journal of Engineering Science Inventions, vol. 4 Issue 3, PP.07-14, March 2015.

[2] M Saifizi, and T W Lee, "Development and investigation of thermoelectric cooling performance based on space scales," International Conference on Advanced Manufacturing and Industry Applications, vol. 429 , pp. 012-083, 2018.

[3] Sundayani, Fabiola Magdalena Prasetyawati, Asep Suhendi, Dyan Franco Sinulingga, Firmawan Matutu Palebangan,and Indra Wahyuddin Fathonah, "PID Temperature Controlling of Thermoelectric Based Cool Box , "International Conference on Control, Electronics, Renewable Energy and Communications, 2017.

[4] M. SH. Nassar, G.I Sulatan, A.A. Hegazi and M.G.Mousa, "Experimental Analysis Of Thermoelectric Cooler Performance using Artificial Neural Network," Novel Intelligent and Leading Emerging Sciences Conference, 2019.

[5] Mohammad Adnan Baloch, Nordin Saad, I.Ismail, and Taj.M.Baloch, "Design and Analysis of PI-FUZZY Controller for Temperature Control System," International Conference onMathematical/Analytical Modelling and Computer Simulation, 2010.

[6] Priyanka Pandey, and Shri S. K. Singh, " A Study on PI and Fuzzy PI Controllers," International Journal of Science Technology \& Engineering, vol. 4, Issue 12, pp. 2349-784, June 2018.

[7] Mohamad Isnaeni Romadhon, Trias Andromeda, Mochammad Facta, and Agung Warsito, "A Comparisson of Synchronous And Nonsynchronous Boost Converter," International Conference on Electrical Engineering, Computer Science and Informatics,2017.

[8] Kairui Cao, and X.Z. Gao, "Stability Analysis of a Type of TakagiSugeno PI-Fuzzy Control Systems Using Circle Criterion," International Journal of Computational Intelligence Systems, vol. 4(2), April 2011.

[9] ANG Ling Yuen, and Fairul Azni Jafar, "Simulation Analysis of Non-linear Fuzzy PID Temperature Controller," Trans Tech Publications, Switzerland,vol. 465-466, pp: 677-681, 2014.

[10] Talar Sadalla, Dariusz Horla, Wojciech Giernacki, and Piotr Kozierski, "Stability Analysisand Tracking Performance of Fractional-Order PI Controller for a Second-Order Oscillatory System with Time-Delay," International Conference on Methods and Models in Automation and Robotics (MMAR), September 2016.

[11] Renny Rakhmawati, Suhariningsih, Janitra Hilmyvarafi Farrasbyan, and Farid Dwi Murdianto, "Performance Robustness of PID Controller in Buck Converter For Cooling System," International Seminar on Application for Technology of Information and Communication (iSemantic), 2018.

[12] Kshitij Rokde, Mitali Patle, TusharKalamdar, Radha Gulhane and Rahul Hiware, "Peltier Based Eco-Friendly Smart Refrigerator for Rural Areas, " International Journal of Advanced Research inComputer Science and Software Engineering, vol. 7, Issue 5, May 2017.

[13] Alfred J. Piggot, and Jeffrey S.Allen, "Peltier Supercooling with Isosceles Current Pulse Cooling an Object with Internal Heat Generation," Journal of Solid State Science and Technology, vol. 6(12), December 2017. 